\title{
Evaluation of DNA extraction from granulocytes discarded in the separation medium after isolation of peripheral blood mononuclear cells and plasma from whole blood
}

\author{
Janná R Murray and Mangalathu S Rajeevan*
}

\begin{abstract}
Background: Whole blood is generally processed for plasma and peripheral blood mononuclear cells (PBMCs) from granulocytes/erythrocytes using gradient centrifugation of blood with Histopaue-Ficoll. After separation of plasma and PBMCs, the residual erythrocytes/granulocytes, a rich source of DNA, is often discarded along with the separation medium. In order to isolate DNA from the granulocytes, current methods require the removal of the separation medium and subsequent purification of granulocytes. This report provides a method for extracting DNA using the PAXgene Blood DNA kit from granulocytes without purifying them from the separation medium.

Findings: Based on 719 erythrocyte/granulocyte samples stored frozen for approximately 10 years in Ficoll-Hypaque separation medium, the mean yield of DNA was $395 \mu \mathrm{g}$ (median $=281 \mu \mathrm{g}$; range $=1.36$ to $2077.2 \mu \mathrm{g}$ ), with mean $A_{260} / A_{280}$ ratio of 1.84 (median $=1.84$; range $=1.17$ to 2.23 ). The quality of isolated DNA was sufficient for use as a template for restriction enzyme digestion, real-time PCR, pyrosequencing, and gel based variable number tandem repeats (VNTR) genotyping.

Conclusions: By demonstrating the extraction of substantial amounts of high quality granulocytes DNA without purifying them from the separation medium, this method offers laboratories and biobanks a flexible and cost-effective approach to obtain plasma, PBMCs, and large amounts of DNA from a single blood collection for a variety of molecular genetics/epidemiologic studies.
\end{abstract}

Keywords: DNA extraction, Granulocytes in separation medium, Whole blood

\section{Findings}

\section{Background}

Whole blood is routinely collected for plasma and PBMC isolation using centrifugation and a density gradient medium such as Ficoll-Hypaque. After centrifugation, whole blood is separated into 4 layers, with plasma at the top followed by white blood cells containing PBMCs, a Ficoll medium layer, and a bottom layer containing erythrocytes and granulocytes (Figure 1) [1]. After the removal of plasma and white blood cells, the remaining Ficoll and the residual erythrocytes/granulocytes, a rich source of genomic

\footnotetext{
*Correspondence: mor4@cdc.gov

Division of High-Consequence Pathogens and Pathology, Centers for Disease Control \& Prevention, 1600 Clifton Rd Mailstop G41, Atlanta, GA 30333, USA
}

DNA for molecular genetic studies, is often discarded. Occasionally, when DNA is required from granulocytes, additional steps to purify them from the separation medium and subsequent DNA extraction steps are needed with the current methods [2-10]. These granulocyte purification steps can include removal of the Ficoll layer, addition of ammonium chloride to the erythrocytes/granulocytes followed by lysis of the erythrocytes, washing, and resuspension of the granulocyte pellet. Further, with the current methods, purification of the granulocytes should be done immediately after blood separation. Here we describe a method that allows for the direct isolation of high quality DNA from stored frozen erythrocytes/granulocytes without purifying them

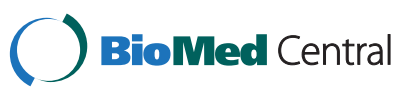




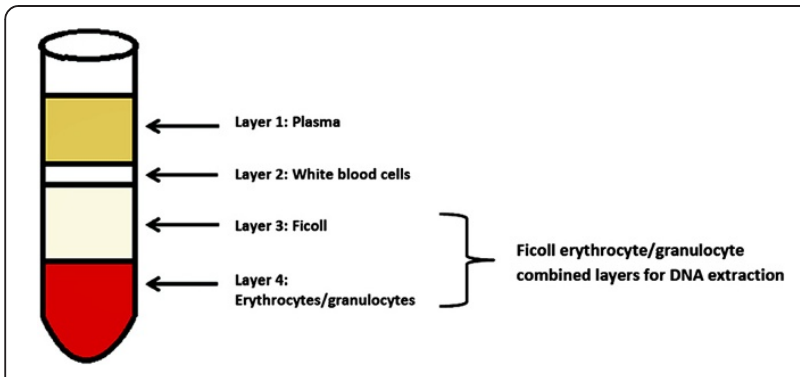

Figure 1 Diagrammatic representation of granulocytes in separation medium evaluated for DNA extraction in this study.

After centrifugation of diluted whole blood over-layed on Ficoll medium, usually plasma (layer 1) and white blood cells (layer 2) are recovered for

further studies. The residual whole blood containing ficoll solution (layer 3) and erythrocytes/granulocytes (layer 4), which is often discarded, was evaluated in this study as a rich source of high quality DNA without further purifications of cells from separation medium.

from the separation medium after removal of the plasma and PBMC layers (Figure 1).

\section{Methods}

Centers for Disease Control \& Prevention (CDC) Human Subjects Committee approved this study that adhered to the human experimental guidelines of the US Department of Health and Human Services and the Helsinki Declaration. All subjects provided informed consent for the study. Peripheral blood was collected in $8 \mathrm{ml}$ sodium citrate tubes, and PBMCs and plasma fractions were removed using Ficoll [11]. The residual solution containing the Ficoll layer and the erythrocytes/granulocytes was stored in a $50 \mathrm{ml}$ centrifuge tube and frozen at $-20^{\circ} \mathrm{C}$ until DNA extraction (approximately 10 years later). Frozen samples were thawed at $37^{\circ} \mathrm{C}$ in a water bath and DNA was extracted using the PAXgene Blood DNA Kit (Qiagen, Valencia, CA, USA). The volume of solution containing the separation medium, erythrocytes, and granulocytes was kept constant at $8 \mathrm{ml}$ with addition of phosphate buffered saline solution (pH 7-7.2) as needed. Subsequently, we followed the PAXgene Blood DNA extraction protocol with these samples. DNA concentration and purity were measured using the Nanodrop ND-1000 Spectrophotometer (Thermo Scientific, Wilmington, DE, USA) and the extract was transferred to a $1.5 \mathrm{ml}$ tube and stored at $-70^{\circ} \mathrm{C}$.

\section{Results}

In this study, we extracted DNA directly from a total of 719 residual erythrocytes/granulocytes in separation medium after the isolation of plasma and PBMC. The average $\mathrm{A}_{260} / \mathrm{A}_{280}$ ratio was 1.84 (range 1.17 to 2.23; median 1.84) with $99 \%$ of the samples being good quality based on $\mathrm{A}_{260} / \mathrm{A}_{280}$ ratio between 1.7 and 2.0. The average yield was $395 \mu \mathrm{g}$ (range 1.36 to $2077.2 \mu \mathrm{g}$; median $281 \mu \mathrm{g}$ ) with $95 \%$ of samples yielding $>50 \mu \mathrm{g}$
DNA per sample. Samples yielded high molecular weight DNA as indicated by electrophoresis in $0.8 \%$ agarose gel and ethidium bromide stain (Figure 2A). We evaluated 10 DNA samples extracted from granulocytes with separation medium for their suitability for restriction enzyme digestion, real time PCR, pyrosequencing, and VNTR genotyping. DNA from a whole blood sample extracted by the same method was included as a control for these evaluations. We observed a nearly complete digestion of DNA (500 ng) in a $50 \mu \mathrm{l}$ reaction containing $50 \mathrm{U}$ each of EcoRV and BamHI enzymes (New England Biolabs, Ipswich, MA, USA) and incubated at $37^{\circ} \mathrm{C}$ for 16 hours (Figure 2A). Granulocyte DNA extracted with separation medium was subjected to LightCycler 480 and SYBR Green dye I (Roche Applied Science, Indianapolis, IN USA) based real time PCR for the amplification of 36B4 (also known as RPLPO) gene using previously published primer sequences [12]. Granulocyte DNA amplified with efficiency (PCR efficiency 1.88) similar to the control whole blood DNA (PCR efficiency 1.89) extracted by the same protocol (Figure 2B). The suitability of granulocyte DNA extracted with separation medium for pyrosequencing was tested by genotyping single nucleotide polymorphism (SNP) rs6112 located in the gene SERPINA5. We designed PCR (forward: ACGCTG TACCTGGCAGACACTT and reverse: CGAGGTTCTT AAGCAAGTCCACAA) and sequencing primers (CCT GGCAGACACTTTC) for rs6112 using the Assay Design Software (Qiagen). Pyrosequencing was done with PyroMark PCR Kit (Qiagen) and PSQ 96 MD (Qiagen) following the manufacturer's instruction. Granulocyte DNA from all 10 samples yielded unambiguous pyrograms and passed automatic genotype calling for rs6112 (Figure 2C). A gel-based assay was used for genotyping of the chemokine receptor 5 (CCR5) VNTR using the PyroMark PCR kit (Qiagen) [13]. PCR bands of expected sizes (157 bp and $189 \mathrm{bp}$ ) were seen with all samples (Figure 2D). From these successful results with a variety of enzymatic assays, granulocyte DNA extracted with the separation medium is expected to work equally well with other molecular genetics assays designed to determine copy number variation, methylation status, etc.

\section{Conclusion}

In conclusion, our work demonstrates that DNA can be extracted directly from the residual solution containing the Ficoll layer and erythrocytes/granulocytes left after the isolation of PBMC's and plasma from whole blood, and that the presence of the separation medium is not a hindrance to extract DNA using the commercially available PAXgene Blood DNA Kit. The quality and quantity of DNA obtained from granulocytes with the separation medium is sufficient enough for a variety of molecular 


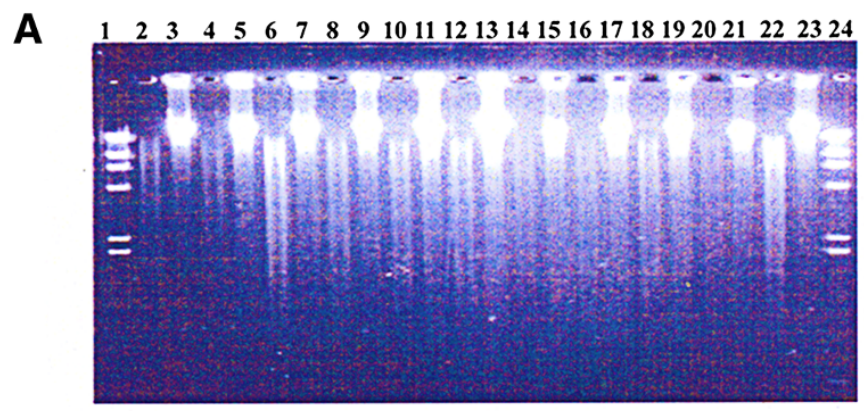

B

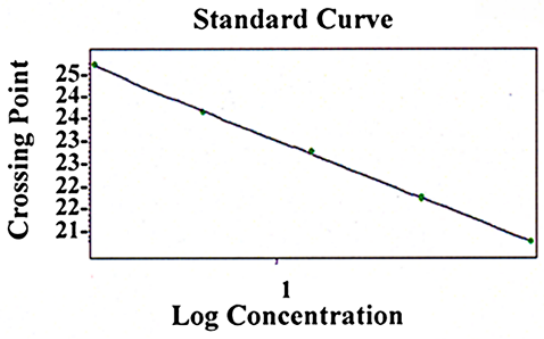

C

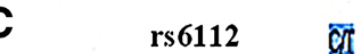

Melting Peaks

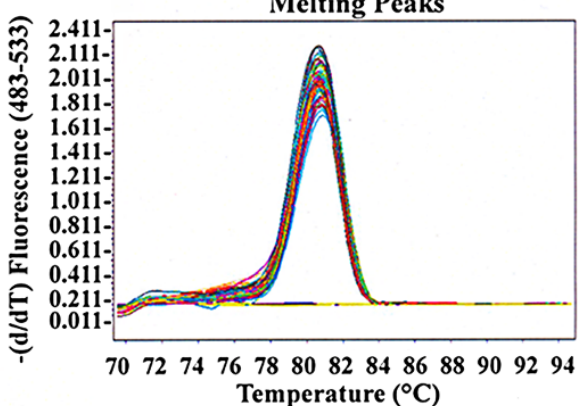

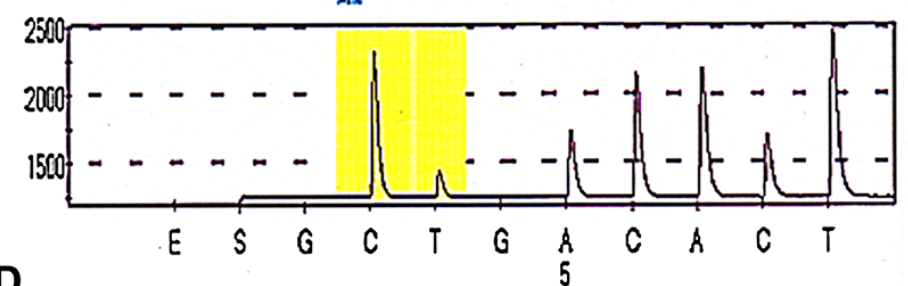

D

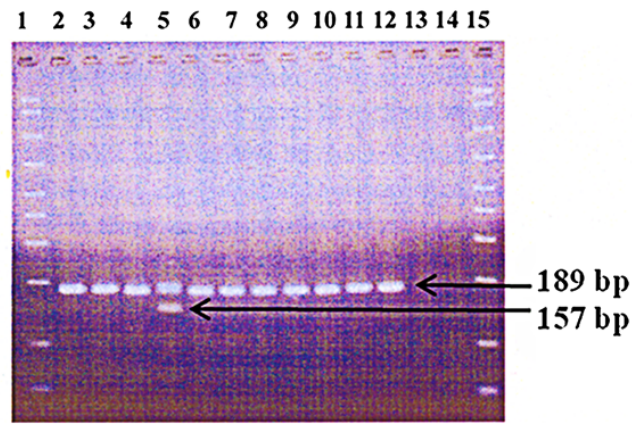

Figure 2 Evaluation of granulocytes DNA extracted with separation medium after isolation of plasma and PBMCs. (A) A $0.8 \%$ agarose gel stained with ethidium bromide demonstrating high molecular weight DNA, and its near complete digestion with EcoRV and BamH1. Lanes 1 and 24 represent the Lambda DNA/HindIII Marker. Lanes 2-21 are a side by side comparison of the digested and undigested granulocyte DNA extracted with separation medium from 10 subjects. Lanes 22-23 represent digested and undigested whole blood DNA for comparison with granulocyte DNA. (B) A typical performance of granulocyte DNA extracted with separation medium in real-time PCR for the $36 B 4$ single copy gene (representative standard curve on the left and melting curves on the right); (C) A representative pyrogram for SNP rs6112 using granulocyte DNA extracted with separation medium for successful genotyping; (D) Gel-based VNTR analysis of the CCR5 VNTR on granulocyte DNA extracted with separation medium and whole blood DNA. Lanes 1 and 15 represent the 50-2,000 bp markers. Lanes 2-11 represent the granulocyte DNAs extracted with separation medium. Lane 12 represents the whole blood DNA and lanes 13 and 14 contain negative water controls. Arrows indicate expected product sizes (189 bp, and $157 \mathrm{bp}$ ) for this VNTR.

genetics assays. Combining quality and yield, $94.3 \%$ (678/719) samples yield $>50 \mu \mathrm{g}$ DNA with an $\mathrm{A}_{260} / \mathrm{A}_{280}$ ratio between 1.7 and 2.0. We recommend that genomic DNA from the remaining small percentage of samples (5.7\%) with low yield and low $\mathrm{A}_{260} / \mathrm{A}_{280}$ ratio may be subjected to whole genome amplification if they need to be recovered in certain situations. Unless purified granulocytes are specifically needed as part of study objective, many laboratories often discard the erythrocytes/granulocytes because of the additional steps 
needed to purify them from the separation medium immediately following the blood separation. Our procedure involves blood collected in sodium citrate tubes, and it will be interesting to compare this method in terms of DNA quality and quantity from residual cells with blood collected in EDTA or heparin coated tubes. In summary, by demonstrating that substantial amounts of high quality DNA can be directly obtained from whole blood residue containing Ficoll solution, erythrocytes, and granulocytes, we have eliminated the need to purify the granulocytes prior to DNA extraction. This method offers laboratories and biobanks a flexible and cost-effective approach to obtain plasma, PBMCs, and large amounts of DNA from a single collection of blood for molecular genetics/epidemiologic studies.

\section{Competing interests}

The authors declare that they have no competing interests.

\section{Authors' contributions}

JRM carried out laboratory experiments and participated in manuscript writing. MSR as Principle Investigator participated in all aspects of the study and drafting of this manuscript. Both authors read and approved the final manuscript.

\section{Acknowledgements}

We acknowledge Dr. Elizabeth R. Unger for her critical suggestions with the preparation of this manuscript. We also acknowledge Mr. Maung Khin for carrying out DNA extraction from a subset of the samples in this study. The findings and conclusions in this report are those of the authors and do not necessarily represent the views of the funding agency.

Received: 28 March 2013 Accepted: 29 October 2013

Published: 1 November 2013

\section{References}

1. Lan K, Verma SC, Murakami M, Bajaj B, Robertson ES: Isolation of human peripheral blood mononuclear cells (PBMCs). Curr Protoc Microbiol 2007, 4(4C):A.4C.1-A.4C.9.

2. Belanger K, Klecker RW Jr, Rowland J, Kinsella TJ, Collins JM: Incorporation of lododeoxyuridine into DNA of Granulocytes in patients. Cancer Res 1986, 46:6509-6512.

3. Flotho C, Steinemann D, Mullighan CG, Neale G, Mayer K, Kratz CP, Schlegelberger B, Downing JR, Niemeyer CM: Genome-wide singlenucleotide polymorphism analysis in juvenile myelomonocytic leukemia identifies uniparental disomy surrounding the NF1 locus in cases associated with neurofibromatosis but not in cases with mutant RAS or PTPN11. Oncogene 2007, 26:5816-5821.

4. Boyum A: Isolation of mononuclear cells and granulocytes from human blood. J Clin Lab Invest 1968, 21(Suppl. 97):77-89.

5. Hamprecht K, Steinmassl M, Einsele H, Jahn G: Disconcordant detection of human cytomegalovirus DNA: from peripheral blood mononuclear cells, granulocytes, and plasma: correlation to viremia and HCMV infection. J Clin Virol 1998, 11:125-136.

6. van Rossum HH, Romijn FP, Sellar KJ, Smit NP, van der Boog PJ, de Fijter JW, van Pelt J: Variation in leukocyte subset concentrations affects calcineurin activity measurement: Implications for pharmacodynamic monitoring strategies. Clin Chem 2008, 54:517-524.

7. Reinius LE, Acevedo N, Joerink M, Pershagen G, Dahlén S, Greco D, Söderhäll C, Scheynius A, Kere J: Differential DNA methylation in purified human blood cells: implication for cell lineage and studies on disease susceptibility. PLOS ONE 2012, 7:e41361.

8. Maqbool M, Vidyadaran S, George E, Ramasamy R: Optimisation of laboratory procedures for isolating human peripheral blood neutrophils. Med J Malaysia 2011, 66:296-299.
9. Savela K, Hemminki K: DNA adducts in lymphocytes and granulocytes of smokers and nonsmokers detected by ${ }^{32} \mathrm{P}$-postlabeling assay. Carcinogenesis 1991, 12:503-508.

10. Fang J, Vaca CE: Detection of DNA adducts of acetylaldehyde in peripheral white blood cells of alcohol abusers. Carcinogenesis 1997, 18:627-632.

11. Vernon S, Shukla SK, Conradt J, Unger ER, Reeves WC: Analysis of $16 \mathrm{~S}$ rRNA gene sequences and circulating cell-free DNA from plasma of chronic fatigue syndrome and non-fatigued subjects. BMC Microbiology 2002, 2:39.

12. Cawthon R: Telomere measurement by quantitative PCR. Nucleic Acids Research 2002, 30:e47.

13. Huang Y, Paxton WA, Wolinsky SM, Neumann AU, Zhang L, He T, Kang $S$, Ceradini D, Jin Z, Yazdanbakhsh K, Kunstman K, Erickson D, Dragon E, Landau NR, Phair J, Ho DD, Koup RA: The role of a mutant CCR5 allele in HIV-1 transmission and disease progression. Nature 1996, 2:1240-1243.

doi:10.1186/1756-0500-6-440

Cite this article as: Murray and Rajeevan: Evaluation of DNA extraction from granulocytes discarded in the separation medium after isolation of peripheral blood mononuclear cells and plasma from whole blood. BMC Research Notes 2013 6:440.

\section{Submit your next manuscript to BioMed Central and take full advantage of:}

- Convenient online submission

- Thorough peer review

- No space constraints or color figure charges

- Immediate publication on acceptance

- Inclusion in PubMed, CAS, Scopus and Google Scholar

- Research which is freely available for redistribution 